\title{
Assessment of the Impacts of Climate Change on Climatic Zones over the Korean Peninsula
}

\author{
Se Jin Jeung, ${ }^{1}$ Jang Hyun Sung, ${ }^{2}$ and Byung Sik Kim $\mathbb{D}^{1}$ \\ ${ }^{1}$ Kangwon National University, Department of Urban Environment \& Disaster Management Engineering, \\ School of Disaster Prevention, 346 Joongang-ro, Samcheok-si, Gangwon-do 25913, Republic of Korea \\ ${ }^{2}$ Ministry of Environment, Han River Flood Control Office, Seocho-gu 06501, Seoul, Republic of Korea \\ Correspondence should be addressed to Byung Sik Kim; hydrokbs@kangwon.ac.kr
}

Received 1 June 2019; Revised 17 September 2019; Accepted 26 September 2019; Published 11 November 2019

Academic Editor: Federico Porcù

Copyright (C) 2019 Se Jin Jeung et al. This is an open access article distributed under the Creative Commons Attribution License, which permits unrestricted use, distribution, and reproduction in any medium, provided the original work is properly cited.

\begin{abstract}
In assessing the impact of climate change, the use of a multimodel ensemble (MME) is required to quantify uncertainties between scenarios and produce downscaled outlines for the simulation of climate under the influence of different factors including topography. This study of climate change scenarios from 13 global climate models (GCMs) assesses the impacts of future climate change. Unlike South Korea, North Korea lacks studies using climate change scenarios of the Coupled Model Intercomparison Project Phase 5 (CMIP5) and only recently did the country start the projection of extreme precipitation episodes. As such, one of the main purposes of this study is to predict changes in the average climatic conditions of North Korea in the future. The result of comparing downscaled climate change scenarios with observation data for a reference period indicates the high applicability of the MME. Furthermore, this study classifies climatic zones by applying the Köppen-Geiger climatic zones classification to the MME, which is validated for future precipitation and temperature. The result suggests that the continental climate that covers the inland area for the reference climate is expected to shift into the temperate climate. Moreover, the coefficient of variation $(\mathrm{CV})$ in the temperature ensemble is particularly low for the southern coast of the Korean Peninsula, and, accordingly, a high possibility of the shifting climatic zone of the coast is predicted.
\end{abstract}

\section{Introduction}

Currently, climate change introduces subtropical vegetation as well as insect and fish species in Korea, with a rising interest in climatic zone classification and the subtropical climatic zone. The Fourth Assessment Report of the Intergovernmental Panel on Climate Change [1] expected that climate change would increase rainfall at $70^{\circ} \mathrm{C}$ or higher northern latitude and polar areas, with the subtropical climatic zone extending up to $30^{\circ} \mathrm{C}$ northern and southern latitude. Such changes in climatic zones will likely have a significant impact on agriculture, fishery, ecosystem, and the daily lives of people. For example, for the past 30 years, major tree species in Korea, such as forsythias, azaleas, and oriental cherry, bloomed six to eight days earlier than expected [2]. Therefore, Seo and Kim [3] showed the impact of climate change on the growth and quality of fruits. They proposed the necessity of new cultivation techniques and alternative species for apples because climate change causes the cultivation areas for apples to slowly shift northward and decrease in South Korea. On the other hand, Sun and Wang [4] suggested that the climate in northeast China has been warmer and drier from 1961 to 2014, which can greatly contribute to the intensification of heat waves and drought in the Korean Peninsula located in a westerly area and easily affected by China's climate. In 2018, the country saw a greater number of heat wave days (31.4) and tropical nights (17.7) compared to the average levels, which are 9.8 days and 5.1 days, respectively. The abnormal increase in temperatures nationwide shows that the country is becoming subtropical. Such climatic zones can be classified with different criteria, but most of the related studies across the world refer to the classification proposed by [5-7] because of its simple calculation [8]. 
Projected future changes in climatic zones mainly use global climate models (GCMs), the regional climate model (RCM), or long-term reanalysis data and classification of Köppen and Köppen-Geiger [9-12]. The research by [9] is one of the most widely known studies that applied the scenarios of a general circulation model (GCM) and the Köppen climatic divide (C/D) to identify major climate characteristics in glacial and interglacial periods. As such, [10] assessed the sensitivity of the Köppen C/D for the longterm time series. On the other hand, [11] determined the climate variability in the Central United States of the 20th century using the Köppen C/D. Meanwhile, Fraedrich et al. [12] also applied the Köppen C/D to identify the change in extent for each of the climatic zones from 1901 to 1995 using climate research unit (CRU) data. Furthermore, Wang and Overland [13] modified the Köppen C/D to analyze the Arctic climate change in the 20th century. Moreover, Beck et al. [14] assessed the changing area of climatic zones for each continent using the monthly average temperatures of the CRU from 1951 to 2000 as well as the monthly precipitation data of the Variability Analysis of Surface Climate Observations (VASClimO) provided by the Global Precipitation Climatology Centre (GPCC) of Germany. The result showed that, in Asia, there had been a significant decrease in the polar climate. Grieser et al. [15] also applied the Köppen C/D using the reanalysis data for 1975 to 2000, while Chung and Shin [16] used observation data to analyze changes in the area of the Köppen $\mathrm{C} / \mathrm{D}$ and the characteristics of desertification. Recently, most of the studies apply the Köppen-Geiger climatic zones classification scheme to intensively analyze climatic zones for small-scale areas.

As Korea's topography is particularly susceptible to the impacts of climate change, downscaling is essential for related studies on the peninsula. The past statistical downscaling assumed that the future climate has the same pattern of spatial/temporal distribution with the current one, so it does not follow the basic principle for climate change. However, it can be useful for bias correction to past observations for quantitative comparisons and easy transition to high-resolution data. Nonetheless, it does not reflect changing climate systems, and trials are being made to combine dynamical downscaling with the statistical method $[17,18]$. Recently, [18] highlighted the necessity of preserving the long-term trends of climate models using quantile delta mapping (QDM). With a growing demand for the analysis of climate change impact, scenarios have been provided in the combination of various factors including weather, atmosphere, continent, and glacier. However, uncertainties between scenarios should be considered because of their high variability. For this reason, an increasing number of studies use the multimodel ensemble (MME), which predicts climate change by combining results from different models [19-21]. South Korea also noticed the wide use of MME across the world. As such, the Korea Meteorological Administration (KMA) implements a certification system to encourage the application of diverse standard scenarios, particularly the 13 scenarios of GCMs.

In this regard, this study applied the Köppen-Geiger climatic zones classification to the climate change scenarios, which are downscaled with having the 13 scenarios of GCMs at a point scale. Moreover, the second section introduces the data and methodology used for this study, and the third section assesses the performance of the scenarios at a point scale by comparing them with observation data. The fourth section, on the other hand, predicts the climate change of the late 21 st century under the Representative Concentration Pathways (RCP 8.5). Lastly, the fifth section summarizes the study and provides a conclusion.

\section{Methods and Data}

\subsection{Method}

2.1.1. Overview. An MME is required to quantify an uncertainty between a downscaled climate change scenario and a raw scenario to identify the shift of climatic zones in the future with the changing climate. In this regard, this study collected the 13 climate change scenarios of GCMs that are recommended by the KMA. It used AIMS (APCC Integrated Modeling Solution, http://aims.apcc21.org/) to produce a downscaled scenario at the scale of 80 observation points in South Korea and North Korea.

An analysis was conducted to compare the reference climates of such a downscaled scenario with the observed climates (temperature and precipitation) for the performance assessment of downscaling. Then, the study used the RCP 8.5 climate change scenario to predict the shift of future climatic zones over the Korean Peninsula in the 21st century. Moreover, RCP 8.5 was selected to reflect extreme climate change conditions (Figure 1).

2.1.2. Köppen-Geiger Climatic Zones Classification. The Köppen-Geiger climatic zones classification is one of the most widely known schemes for classifying climates. Originating from the first trial of Köppen in 1918 for grouping the world's climates, the method was modified in 1936 and underwent two instances of remodification by Geiger (1954) in 1954 and 1961 to produce the KöppenGeiger climatic zones classification. This scheme is grouped in three consecutive letters (first to third; Table 1). The first letter divides climates into five climate subgroups: A (tropical), B (dry), C (temperate), D (continental), and E (polar and alpine). On the other hand, the second letter indicates the seasonal precipitation type, while the third letter indicates the level of temperature.

\subsection{Data}

2.2.1. Climate Change Scenario. The KMA operates a certification system to encourage the use of diverse scenarios. The system recommends 13 scenarios at a regional level that are produced with the combination of GCMs scenarios and statistical downscaling (Table 2). For such statistical downscaling, the spatial disaggregation with quantile delta mapping (SDQDM; Eum and Cannon, 2017) has been recommended as it was designed to preserve climate models' 


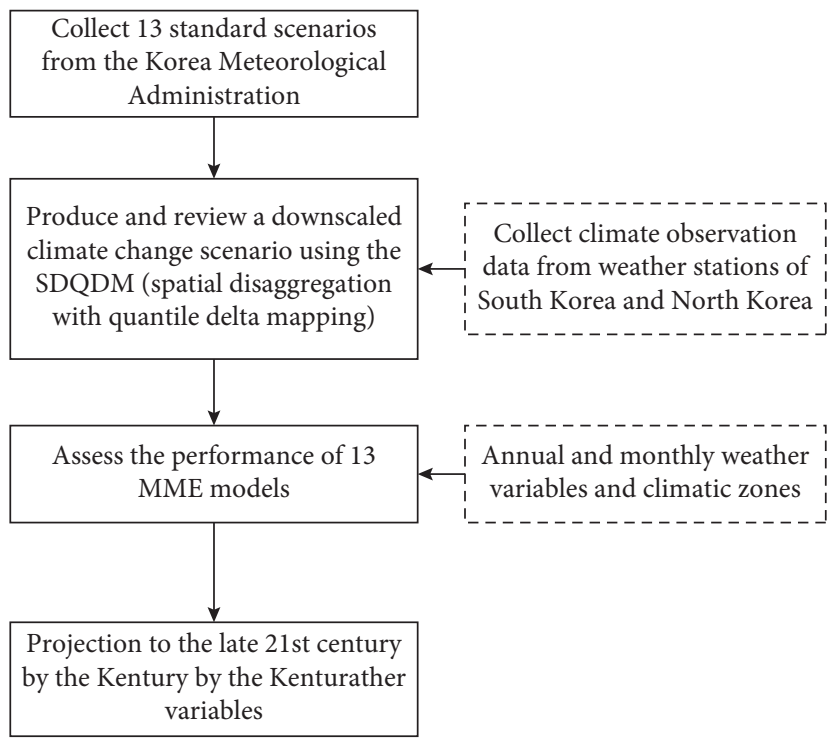

FIgURE 1: Research procedure.

TABle 1: Köppen-Geiger climatic zones classification.

\begin{tabular}{|c|c|c|c|c|c|}
\hline & First & & Second & & Third \\
\hline $\begin{array}{l}\text { A } \\
\text { Tropical climates }\end{array}$ & $\begin{array}{l}\text { Average temperatures } \\
\text { of } 18^{\circ} \mathrm{C}\end{array}$ & $\mathrm{f}$ & $\begin{array}{l}\text { Wet climate; monthly precipitation } \\
\text { is more than } 60 \mathrm{~mm}\end{array}$ & $\mathrm{~h}$ & $\begin{array}{c}\text { Annual mean temperature } \\
\text { over } 18^{\circ} \mathrm{C}\end{array}$ \\
\hline $\begin{array}{l}\text { B } \\
\text { Dry climates }\end{array}$ & $\begin{array}{l}\text { Annual rainfall of less } \\
\text { than } 50 \mathrm{~mm}\end{array}$ & $\mathrm{~m}$ & $\begin{array}{l}\text { Monsoon climate; monthly rainfall } \\
\text { of one to three months is less than } \\
\qquad 60 \mathrm{~mm}\end{array}$ & $\mathrm{k}$ & $\begin{array}{c}\text { Annual mean temperature of less } \\
\text { than } 18^{\circ} \mathrm{C}\end{array}$ \\
\hline $\begin{array}{l}\text { C } \\
\text { Temperate } \\
\text { climates }\end{array}$ & $\begin{array}{l}\text { Annual minimum } \\
\text { temperature }-3^{\circ} \mathrm{C} \text { to } 18^{\circ} \mathrm{C}\end{array}$ & $\mathrm{w}$ & $\begin{array}{c}\text { Wet savannah climate; summer } \\
\text { precipitation }>10 \times \text { winter } \\
\text { precipitation }\end{array}$ & $\mathrm{a}$ & $\begin{array}{c}\text { Annual maximum temperature } \\
\text { over } 22^{\circ} \mathrm{C}\end{array}$ \\
\hline $\begin{array}{l}\text { D } \\
\text { Continental } \\
\text { climates }\end{array}$ & $\begin{array}{l}\text { Highest annual temperature } \\
\text { above } 10^{\circ} \mathrm{C} \text { minimum annual } \\
\text { temperature less than }-3^{\circ} \mathrm{C}\end{array}$ & $\mathrm{s}$ & $\begin{array}{l}\text { Dry savannah climate; summer } \\
\text { precipitation }>3 \times \text { winter } \\
\text { precipitation }\end{array}$ & $\mathrm{b}$ & $\begin{array}{l}\text { Annual maximum temperature of } \\
\text { less than } 22^{\circ} \mathrm{C} \text {; the month with an } \\
\text { average monthly temperature of } \\
10^{\circ} \mathrm{C} \text { or more lasts for four months } \\
\text { or more }\end{array}$ \\
\hline \multirow[t]{4}{*}{$\begin{array}{l}\text { E } \\
\text { Polar and alpine } \\
\text { climates }\end{array}$} & $\begin{array}{c}\text { Annual maximum temperature } \\
\text { less than } 10^{\circ} \mathrm{C}\end{array}$ & W & $\begin{array}{l}\text { Desert climate; mid-latitude rainfall } \\
\text { below } 250 \mathrm{~mm}\end{array}$ & C & $\begin{array}{l}\text { Average summer temperature is } \\
\text { below } 22^{\circ} \mathrm{C} \text {; months with an average } \\
\text { temperature of } 10^{\circ} \mathrm{C} \text { or higher per } \\
\text { month are less than three months }\end{array}$ \\
\hline & & $S$ & $\begin{array}{c}\text { Steppe climate; mid-latitude } \\
\text { precipitation more than } 250 \mathrm{~mm}\end{array}$ & $\mathrm{~d}$ & $\begin{array}{c}\text { Average temperature in winter is } \\
\text { below }-38^{\circ} \mathrm{C}\end{array}$ \\
\hline & & $\mathrm{T}$ & $\begin{array}{l}\text { Tundra climate; highest annual } \\
\text { temperature of } 0^{\circ} \mathrm{C} \text { or higher }\end{array}$ & & \\
\hline & & $\mathrm{F}$ & $\begin{array}{l}\text { Ice and snow climate; annual } \\
\text { temperature below } 0^{\circ} \mathrm{C}\end{array}$ & & \\
\hline
\end{tabular}

long-term trends and conduct bias correction. This study used MME results from 13 models under RCP 8.5, which expects no mitigation of greenhouse gases as an extreme case (IPCC, 2014). Figure 2 shows the location of the weather station used for the downscaled.

2.2.2. Climate Observation Data. The S-shaped Korean Peninsula measures about $1,013.2 \mathrm{~km}$ long, but with a short width from east to west. It is shared by South Korea and North Korea with a total area of $227,943.1 \mathrm{~km}^{2}$, with South Korea accounting for about $45 \%$ of the territory and $67 \%$ of the total population, while North Korea for 55\% and 33\%, respectively. Regarding administrative division, South Korea has a special city (si in Korean), six metropolitan cities, eight provinces (do in Korean), one special governing city, and one special governing province. On the other hand, North Korea has a city under direct control, two special cities, and nine provinces. The peninsula has a topographical feature with high eastern and low western areas. In South Korea, only Gimje and Cherwon do not have mountain surfaces.

Such geological and topographical features cause the peninsula to manifest various climatic zones despite its small 
TABLE 2: Thirteen GCMs used for the study.

\begin{tabular}{lccc}
\hline No. & GCMs & Resolution (degree) & Institution \\
1 & CanESM2 & $2.813 \times 2.791$ & Canadian Centre for Climate Modeling and Analysis \\
(CCCMA) & National Center for Atmospheric Research (NCAR) \\
2 & CESM1-BGC & $1.250 \times 0.942$ & Centro Euro-Mediterraneo per I Cambiamenti \\
3 & CMCC-CM & $0.750 \times 0.748$ & Climatici \\
4 & CMCC-CMS & $1.875 \times 1.865$ & Centre National de Recherches Météorologiques \\
5 & CNRM-CM5 & $1.406 \times 1.401$ & Geophysical Fluid Dynamics Laboratory \\
6 & GFDL-ESM2G & $2.500 \times 2.023$ & Met Office Hadley Centre for Climate Science and \\
7 & HadGEM2-AO & $1.875 \times 1.250$ & Services \\
8 & HadGEM2-ES & $1.875 \times 1.250$ & Institute of Numerical Mathematics \\
9 & INM-CM4 & $2.000 \times 1.500$ & Institut Pierre Simon Laplace \\
10 & IPSL-CM5A-LR & $3.750 \times 1.895$ & Meteorological Research Institute \\
11 & IPSL-CM5A-MR & $2.500 \times 1.268$ & Norwegian Climate Centre \\
12 & MRI-CGCM3 & $1.125 \times 1.122$ & $2.500 \times 1.895$ \\
\hline
\end{tabular}

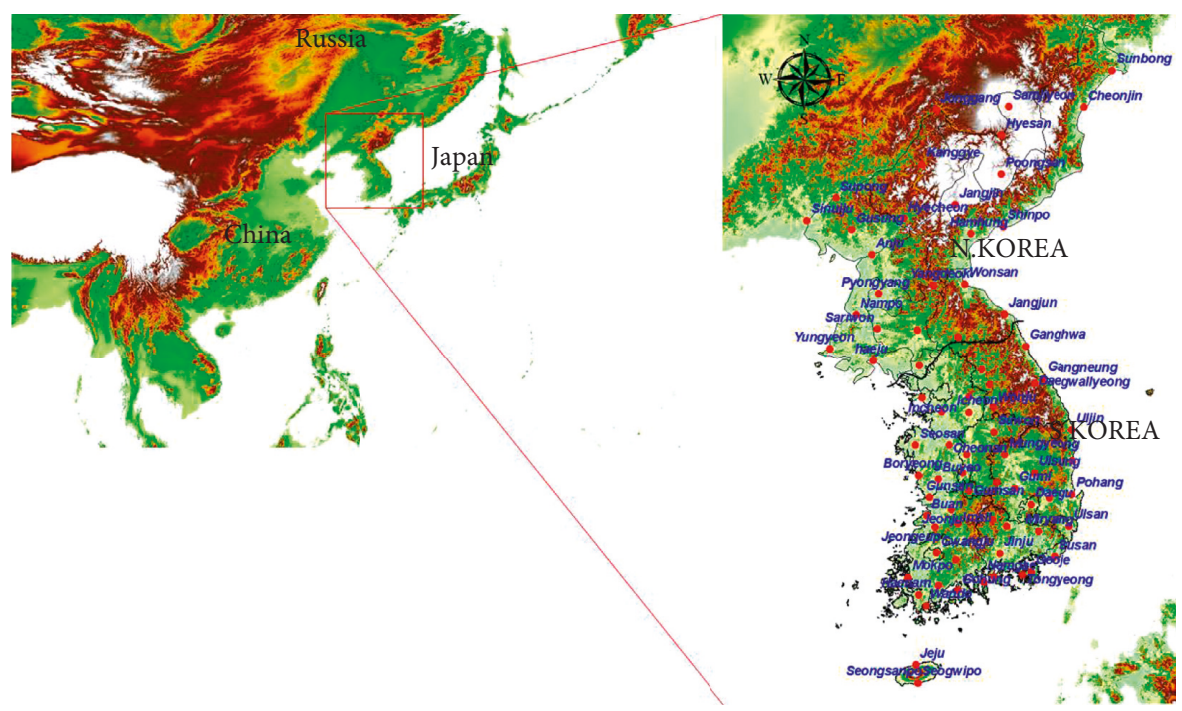

FIGURE 2: Weather stations used for the analysis.

area. Temperatures start increasing from March, reach the highest in August, and decrease in October. In particular, Korea's winter temperature is second highest at the same latitude after the steep sections of Himalaya. South Korea has $1,347 \mathrm{~mm}$ of annual mean precipitation, while North Korea has about $970 \mathrm{~mm}$, which is only about $72 \%$ of that of South Korea. Furthermore, the annual mean temperature of South Korea is $14.1^{\circ} \mathrm{C}$, which is $4.8^{\circ} \mathrm{C}$ higher than that of North Korea. Figure 3 shows the annual mean precipitation and mean temperature observed across the Korean Peninsula. High annual precipitation is reported for hilly section areas near the Taebaek Mountains and northern areas in Gangwon-do and middle areas (Figure 3(a)) because of topographical factors of Taebaek and Gangwon as well as vapors moving from the west coast to middle areas. As such, the Taebaek Mountains and northwestern areas in North Korea show low annual mean temperatures (Figure 3(b)).

\section{Performance of Climate Change Scenarios}

To verify the performance of MME from the 13 climate change scenarios of GCMs, this study draws a box plot, using spatially calculated averages for monthly precipitation and mean temperature data provided by 80 weather stations for the reference period for each of the models. In addition, the coefficient of variation $(\mathrm{CV})$ between models was calculated by station point for the annual precipitation and average temperatures of the late $21 \mathrm{st}$ century (2071-2100).

3.1. Downscaling of Climate Change Scenarios. This study statistically downscaled the 13 national standard scenarios, using the SDQDM of the AIMS provided by the Asia Pacific Economic Cooperation Climate Center (APCC). In this section, the study compares the probability density functions (PDFs) and spatial distribution between MME (precipitation and temperature), which is downscaled for the period of reference climate, and observation data. This aims to verify the applicability of statistical downscaling results. For North Korea's climate observation, the study used data from 27 points sent through the Global Telecommunication System (GTS) of the World Meteorological Organization (WMO). 


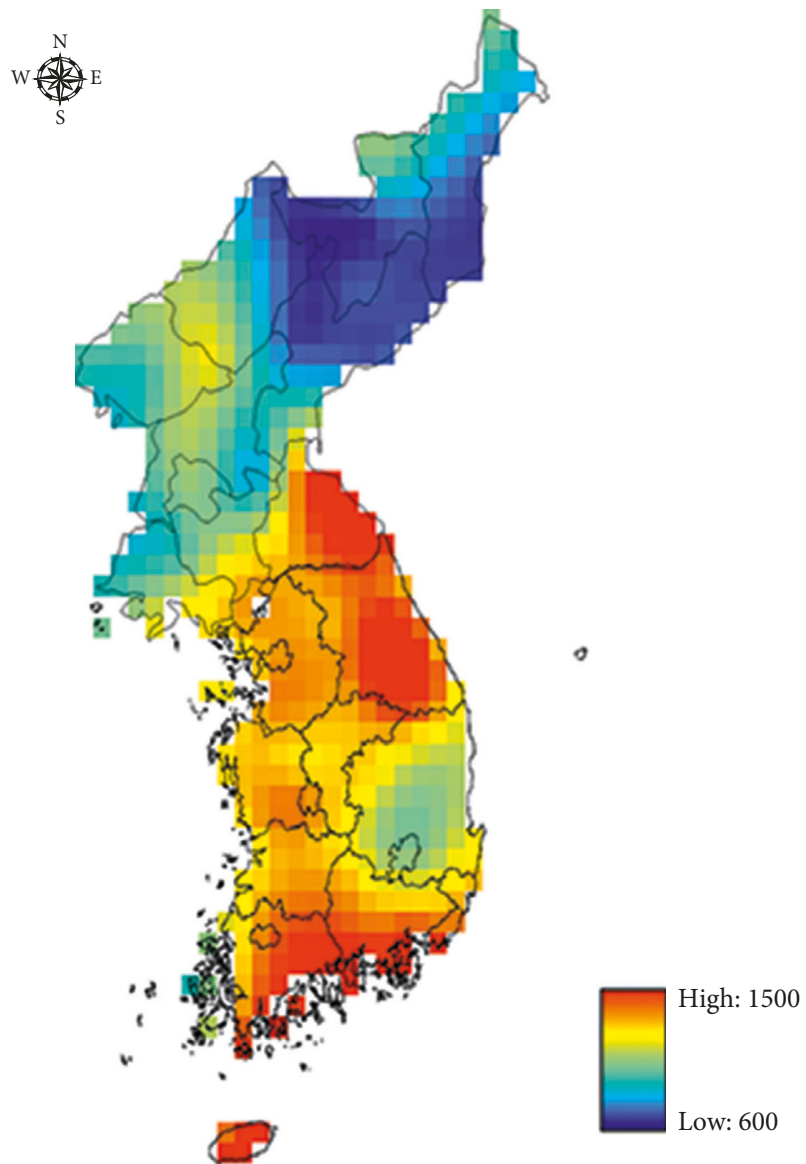

(a)

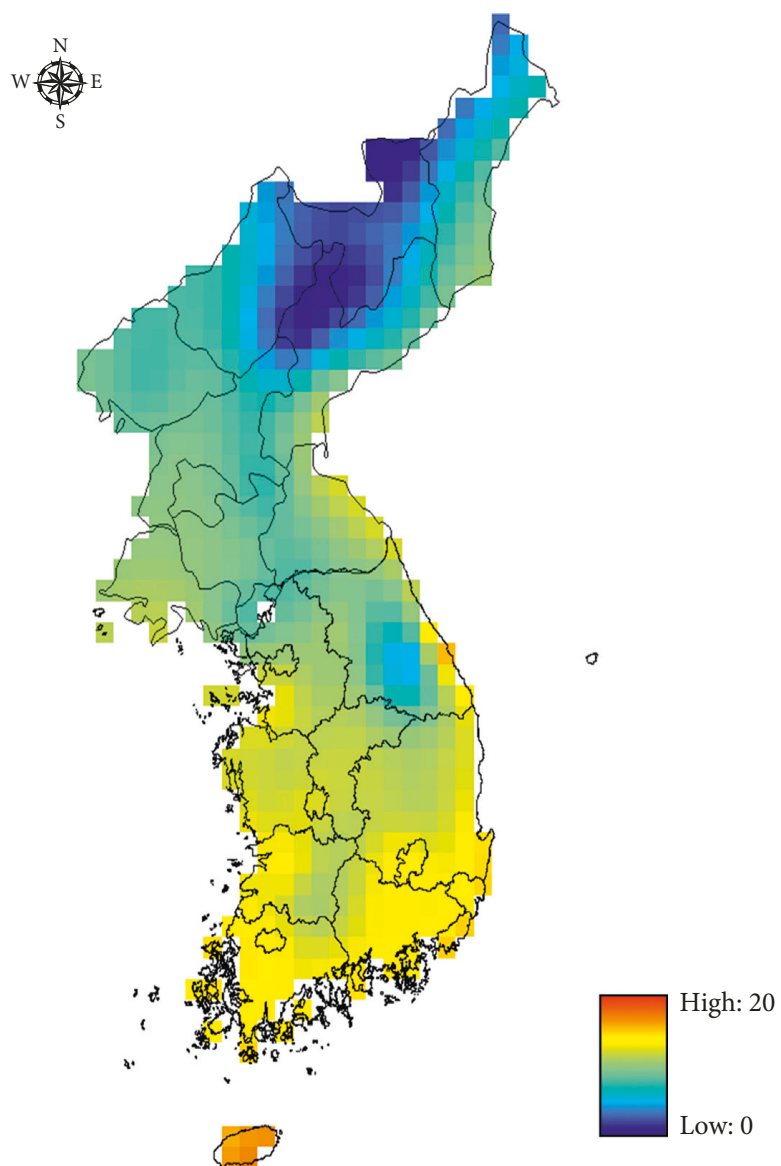

(b)

FIgURE 3: Annual precipitation and average temperatures over the Korean Peninsula. (a) Annual precipitation. (b) Annual average temperatures.

3.1.1. Annual Characteristics. For annual precipitation, the PDFs were compared between the observation data and before or after the application of the SDQDM. This is well matched to the bell-shaped, normal distribution for the average value, while variables were gathered around the median. Comparing average values (mode and median) and variances before downscaling (blue line in Figure 4) and after downscaling (red line in Figure 4), the study found that they were well matched to those of observation data after downscaling. For quantitative results, the average value of OBS is $1,116 \mathrm{~mm}$, the average of raw scenario is 1,196 , and the average of downscaled scenario is $1162 \mathrm{~mm}$. Moreover, it is confirmed that data of the observation and after downscaling are similar. The result of comparing spatial distribution before and after downscaling suggested that the latter simulated the spatial distribution very close (Figures 5(a) and 5(c)) to that of observation data (Figure 5(a)). In particular, its simulation of spatial distribution for precipitation under the influence of the topography was highly accurate to show high precipitation in southern and eastern areas of South Korea during low precipitation in northern [[parms resize(1),pos(50,50),size (200,200),bgcol(156)]]l, climate models secure high performance for temperatures. Thus, unlike the example for precipitation above, the raw

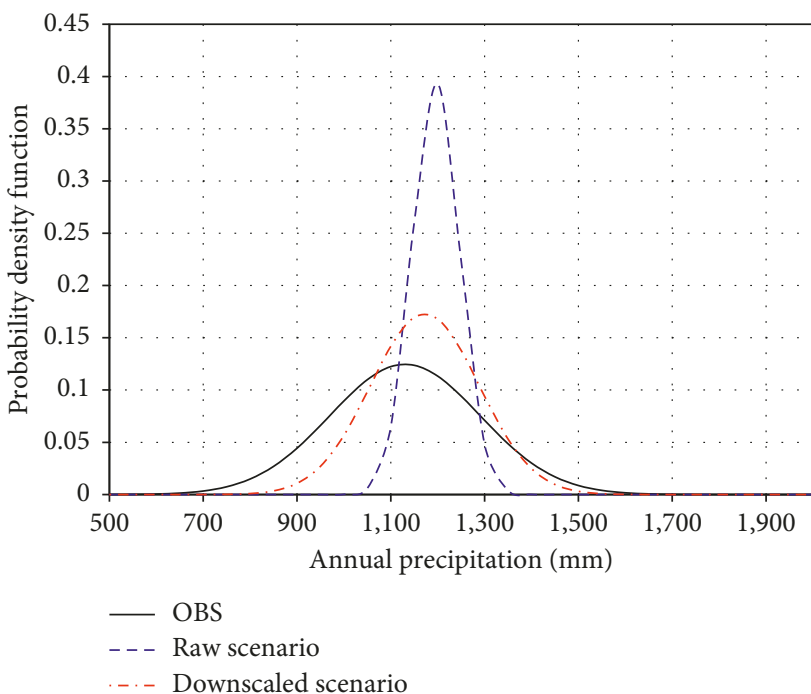

FIGURE 4: Observation and probability density functions before and after application of SDQDM (annual precipitation).

scenario (before downscaling) also produced temperatures close to the observation data. The average value obtained after downscaling was well matched to that from the 


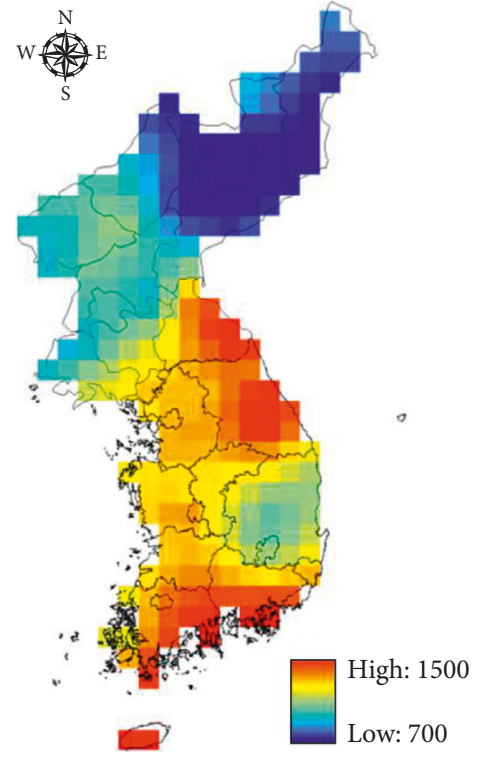

(a)

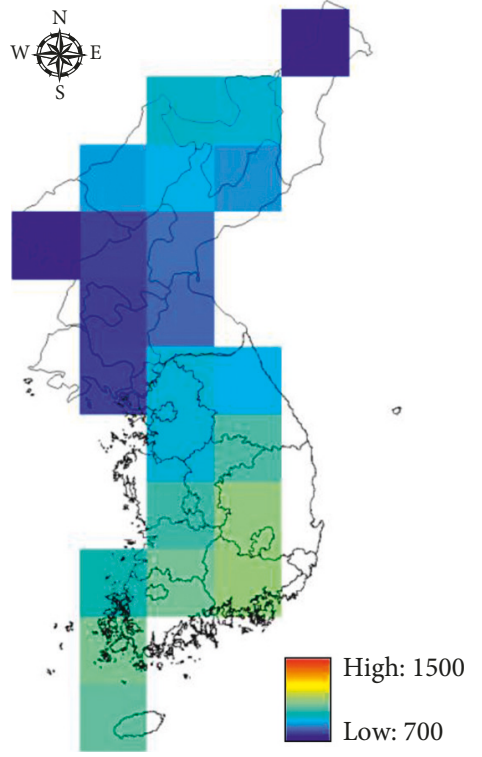

(b)

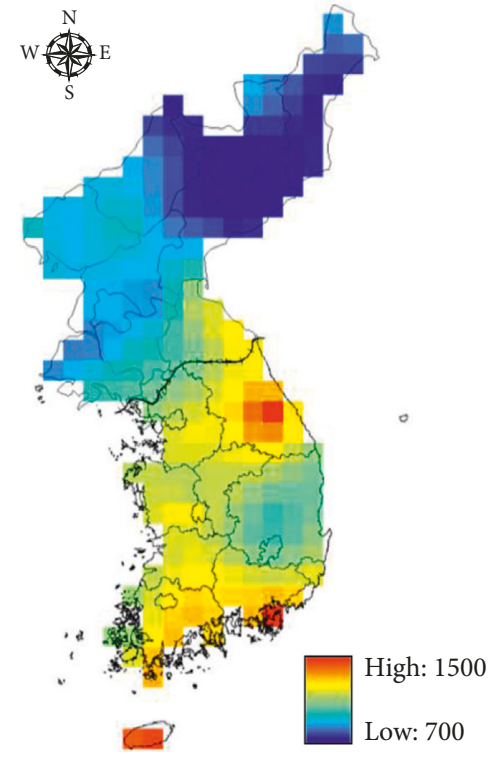

(c)

FIgURE 5: Spatial distribution for observation and before and after downscaling (annual precipitation). (a) OBS. (b) Raw scenario. (c) Downscaled scenario.

observation data; however, there was a slight discrepancy in variance between the two. For quantitative results, the average value of $\mathrm{OBS}$ is $13.3^{\circ} \mathrm{C}$, the average of raw scenario is $12.2^{\circ} \mathrm{C}$, and the average of downscaled scenario is $12.9^{\circ} \mathrm{C}$. Moreover, it is confirmed that data of the observation and after downscaling are similar (Figure 6). The result of comparing spatial distribution after downscaling and that of the observation data showed that the former simulated low temperatures (Figure 7(c)), which are very close to those of the latter (Figure 7(a)) for the Taebaek Mountains, the Kaema Plateau, and the Baekdu Mountain. In addition to such cooler condition simulated for the hilly sections, high temperatures were also simulated close to the observed temperature tendencies for the southern part and eastern coastal areas of South Korea.

3.1.2. Monthly Characteristics. In the above section, the performance was verified for annual precipitation and mean temperatures for the reference period to show the applicability of the downscaling result. However, the high monthly variability in precipitation episodes and temperatures that the Korean Peninsula has experienced require further analysis. As such, Figure 8 presents a box plot for the quantile of monthly precipitation. Each of the boxes indicates the intermodel variability (the top of the graph is the maximum of 13 -model data, the second is the $75 \%$ quantile, the third is the $25 \%$ quantile, and the last is the minimum) of the 13 climate change scenario models, with the blue dotted line for observation and the red line for MME averages. The box plot suggests that MME averages are very close to those from observation data. The months with high precipitation, June and August, see high variability. Moreover, a box plot of the MME was drawn for monthly temperatures as well to see their variability. Figure 9 shows the result of variability

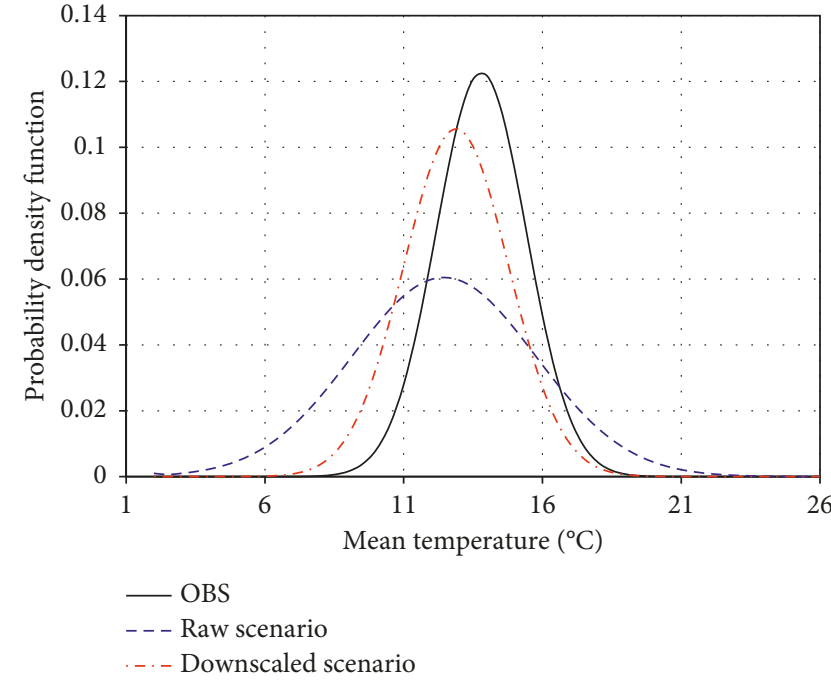

FIGURE 6: Observation and probability density functions before and after application of the SDQDM (average temperature).

analysis for monthly mean temperatures, which indicates that the variability of the climate models is similar between months. It also suggests that MME averages are simulated close to those from observation data.

3.1.3. Climatic Zone. Climate is generally understood as the average weather conditions of an area over 30 years. As it reflects the average and change for different variables such as temperature, pressure, humidity, precipitation, wind speed, wind direction, and solar radiation, it is inherently a complex system that varies from region to region. Some parts in South Korea already experience the subtropical 


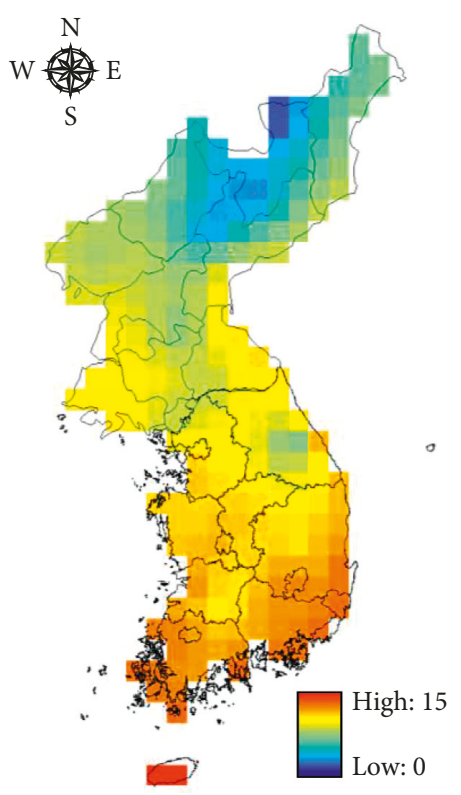

(a)

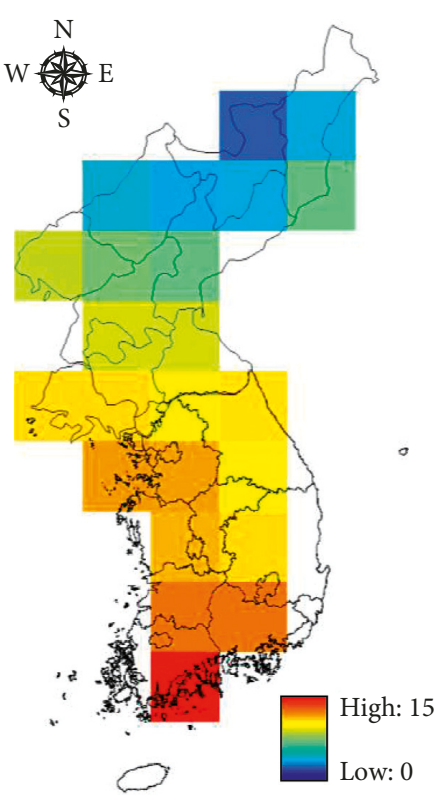

(b)

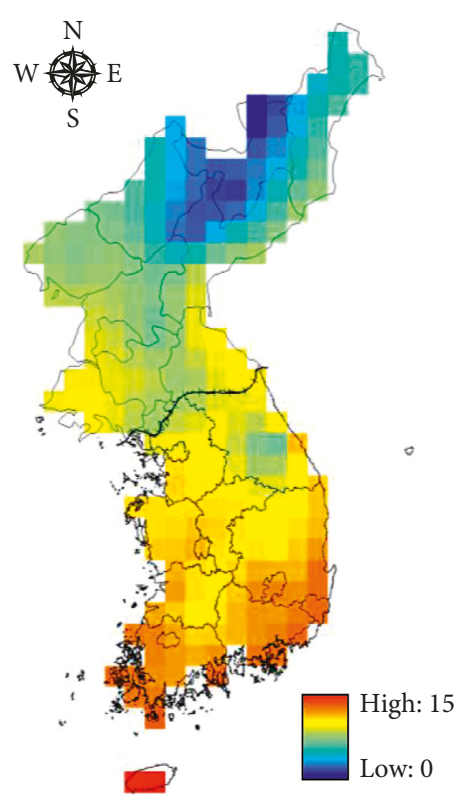

(c)

FIGURE 7: Observation and before/after application of the SDQDM (average temperature). (a) OBS. (b) Raw scenario. (c) Downscaled scenario.

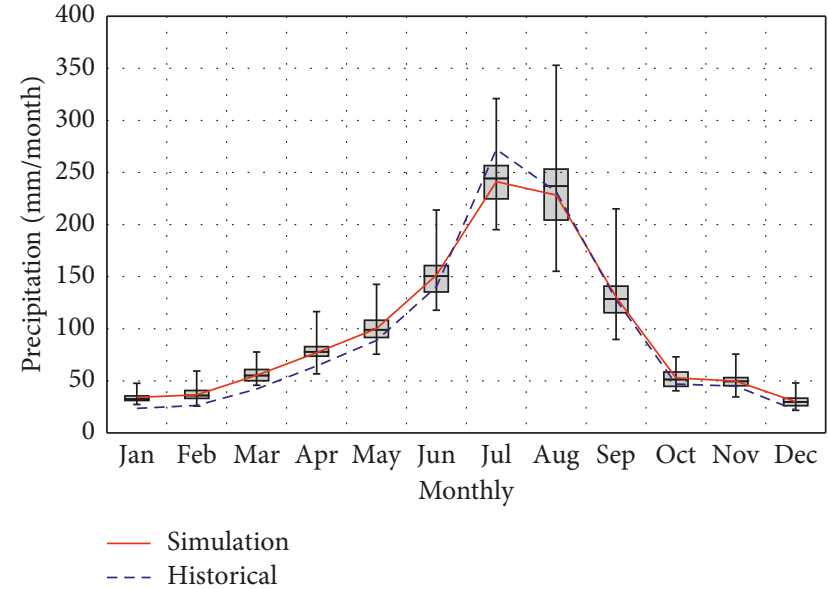

FIGURE 8: Intermodel variability for monthly precipitation.

climate with accelerating climate change, so there has been a growing demand for systematic and quantified analyses of climate change that can provide a scientific foundation to respond to a rapidly changing climate.

In this regard, the study aimed at implementing projection in climatic zones changes of the Korean Peninsula. For this purpose, it used the RCP 8.5 scenario that considers the severest of the available climate change conditions as well as the Köppen-Geiger climatic zones classification, which provides a detailed climate classification. Before the prediction, comparison analysis was conducted between observed data (1986-2005) and results from the MME of 13 models (1986-2005). Table 3 compares the surface area distribution of climatic zones between the past observation and the current climates (simulated results) over the same

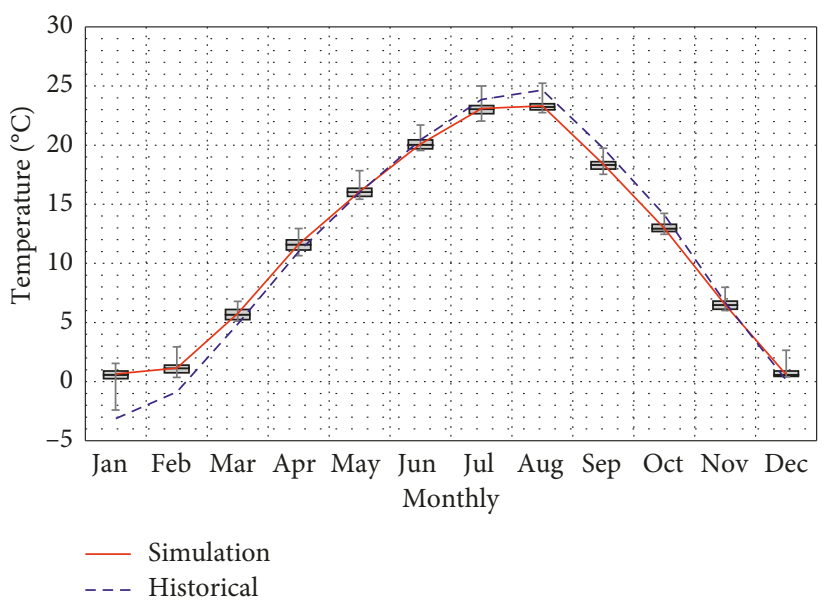

FIGURE 9: Intermodel variability for monthly average temperatures.

TABLE 3: Change in area of four climatic zones for observation and simulated climates (unit: \%).

\begin{tabular}{lcccc}
\hline & Dfb & Dwa & Dfa & Cfa \\
\hline Observation (1986-2005) & 11 & 31 & 44 & 13 \\
Simulation (current) (1986-2005) & 14 & 28 & 43 & 15 \\
\hline
\end{tabular}

Notes: Dfb: continental climate with a warm and humid summer season. Dwa: climate with a hot and dry summer season under the monsoon. Dfa: continental climate with a hot and humid summer season under the monsoon. Cfa: subtropical climate.

period. As a result, area distribution for each of climatic zones had a pattern similarity between the two across the peninsula. However, in the current climate, the Dfb (warm continental climate with high precipitation) and Cfa 
(subtropical) increased by $3 \%$ and $2 \%$, respectively, from the level of the observation. For the Dwa (hot and dry continental climate under the monsoon), the current climate showed $3 \%$ less than the observed one. Figure 10 shows the result of area distribution analysis, and the Cfa covers the southern and middle part of the peninsula, while the Dwa and the Dfb are prevalent over North Korea.

\section{Projection of the Shift of Climatic Zones with Changing Climate}

This study applied the Köppen-Geiger climatic zone classification to predict the shift of the climatic zones for the later 21st century (2017-2100) under the RCP 8.5 scenario, which considers the severest climate change conditions. As such, Table 4 shows a change in extent by the future climatic zone of the Korean Peninsula. The $\mathrm{Dfb}$ disappears over time, and the Dwa is expected to significantly decrease. Moreover, it is noticeable that the Cfa's projection is to increase by $9 \%$ from the level of the current climate. On the other hand, Figure 11 shows the area distribution of climatic zones for 90 years in the future under the RCP 8.5 scenario. The Cfa will possibly extend to Jeolla-do, Gyeongsang-do, mountainous areas in Gangwon-do, and some parts of southern Gyeonggi-do. While the Dfa is predicted to be predominant over the peninsula, the Dfb and Dwa are likely to disappear. As a result, the continental climate (D) that currently covers inland areas will likely shift to the temperate climate $(\mathrm{C})$ in the future because of significant increase in annual precipitation and warming effect (up to $2.9^{\circ} \mathrm{C}$ ) in the regions that will experience the shifting climatic zones, as explained in the above comparison analysis of variability for precipitation and temperatures.

The study calculated the $\mathrm{CV}$ to identify variability between climate change scenarios for predicting average climate conditions. The CV is the ratio of the standard deviation to the mean. In this study, the $\mathrm{CV}$ is a value relative to an average; thus, it is used to compare variation between distributions with different sizes or units. A low $\mathrm{CV}$ indicates a slight discrepancy between models with the average from the models as a middle point. As mentioned, this means that there is a high possibility that the average conditions will occur in the future. Regarding the spatial distribution of the MME's CVs for annual precipitation, they were lower at Jagang-do and Yanggang-do in North Korea but high in the southern coast in South Korea (Figure 12(a)). For annual mean temperature, the lowest CV was found at the southern coast in South Korea (Figure 12(b)). According to the Köppen-Geiger climatic zones classification, the temperature is the criteria, in general, to place climatic zones into the first group. As the southern coast warming was clearly identified with a rise in temperature, and the CVs between models were low, the region will very likely see increasing temperature. This result also indicates a high possibility of change in the climate of watersheds and hydrological cycles in the peninsula with the increasing precipitation and mean temperature.
TABle 4: Projection of shifting climatic zones in the future under the RCP climate change scenario (unit: \%).

\begin{tabular}{lcccc}
\hline & Dfb & Dwa & Dfa & Cfa \\
\hline Current (1981 2005) & 14 & 28 & 43 & 15 \\
Future 1 (2011 2040) & 0 & 32 & 55 & 13 \\
Future 2 (2041 2070) & 0 & 25 & 58 & 17 \\
Future 3 (2071 2100) & 0 & 3 & 73 & 24 \\
\hline
\end{tabular}

This study calculated precipitation (P) and evapotranspiration (ET) for the regions that are expected to experience the shift of climatic zone from the continental climate (D) to the temperate climate (C) in the future, namely, Gyeongsang-do and Jeolla-do. For evapotranspiration, the Thornthwaite method was used (Figure 13). As a result, for Gyeongsang-do, precipitation is projected to increase over time, and the same goes for evapotranspiration with the rise in temperature, but it was analyzed that the P-ET would not be significantly different in the future. For Jeolla-do, precipitation and evapotranspiration are projected to increase over time, and, accordingly, there would be a slight increase in the P-ET, mainly because the increasing trend of precipitation is more significant than that of evapotranspiration, or precipitation outweighs evapotranspiration. The available water is predicted to increase as well with more precipitation. However, Jeolla-do, for which CVs for temperatures were calculated low, will likely experience often droughts in the future as the region has a high possibility of warming, as an average condition, which will lead to a significant increase in evapotranspiration.

\section{Conclusion and Discussion}

This study aimed to assess the impacts of climate change on the shift of climatic zones over the Korean Peninsula. First, the study applied the spatial disaggregation with quantile delta mapping (SDQDM) to 13 global climate models (GCMs) recommended by the Korea Meteorological Administration (KMA) and produced a downscaled scenario for climate change. Second, it evaluated the performance of the multimodel ensemble (MME) for the past climate. Lastly, the study used the produced climate change scenario, which underwent the verification process to project shifting climatic zones of the future Korean Peninsula. The MME averages were matched close to the historical climate, showing its excellent performance. Kwon and Sung [22] compared the monthly precipitation of HadGEM2-AO with observation data across South Korea and showed a significant discrepancy between the simulated precipitation $(436.9 \mathrm{~mm})$ and observation $(706.6 \mathrm{~mm})$ for the rainy season (July to September). However, in this study, the discrepancy between the simulation and observation only reached $37.5 \mathrm{~mm}$ across the peninsula. It was identified that typical rainy regions under the influences of topographical and meteorological conditions were well expressed as a result of the comparative analysis of spatial distribution in addition to overall precipitation.

The Korean Peninsula shows a wide range of climate as it extends long from north to south. North Korea's temperature 


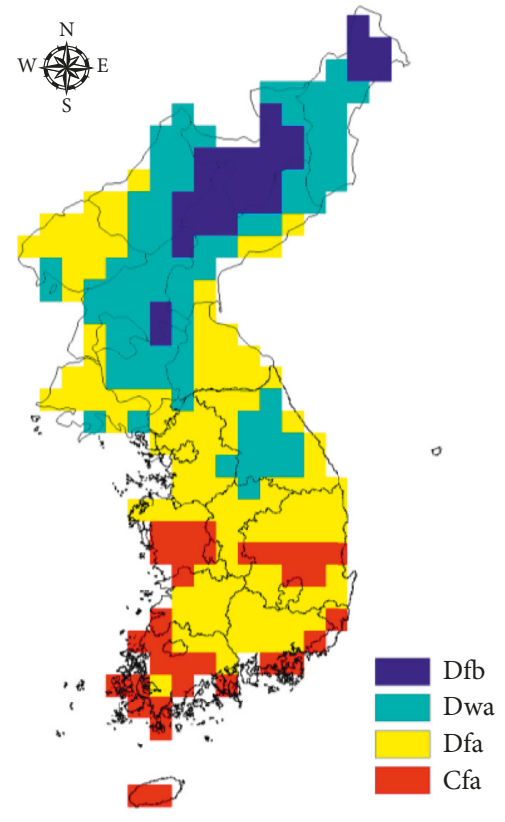

(a)

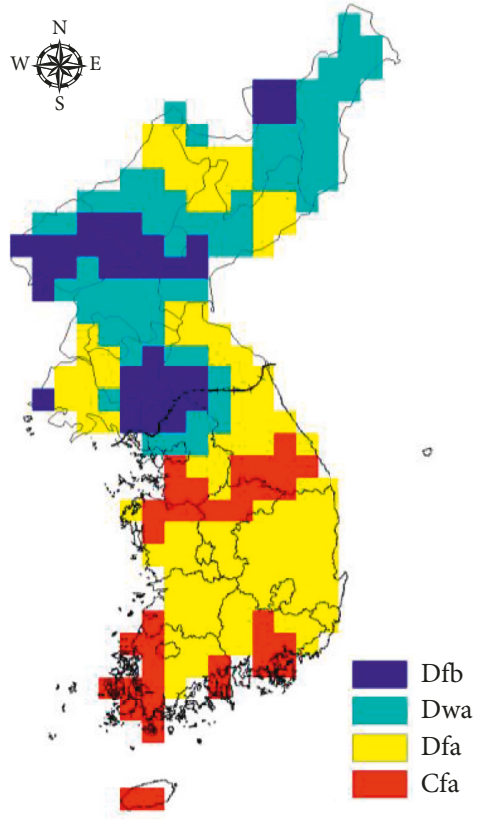

(b)

FIGURE 10: Spatial distribution of climatic zones for observation and simulated climates. (a) Historical. (b) Simulation.

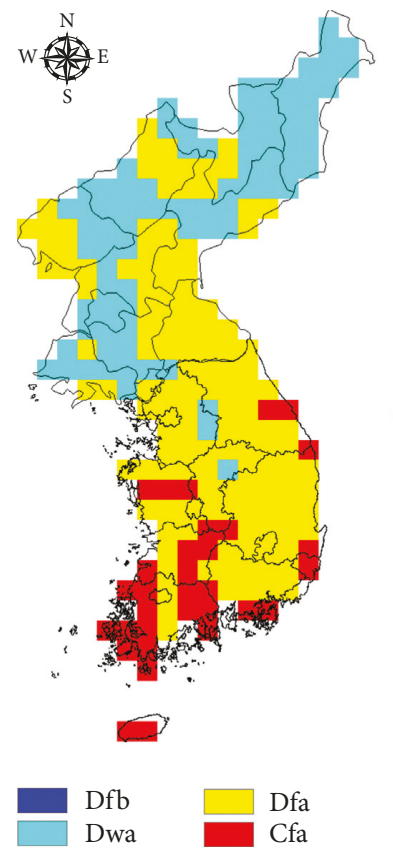

(a)

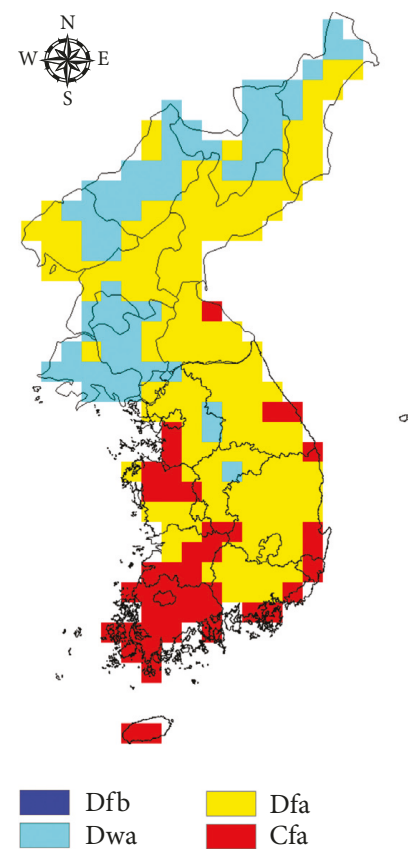

(b)

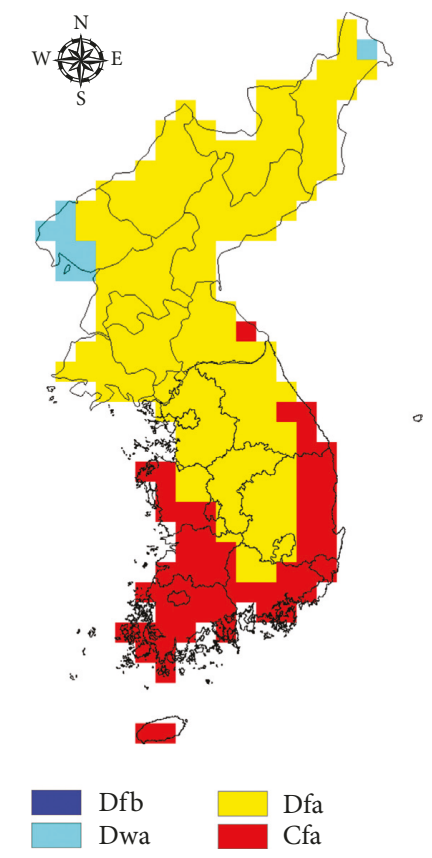

(c)

Figure 11: Projection of climatic zones under the RCP 8.5 climate change scenario. (a) Future 1. (b) Future 2. (c) Future 3.

has risen by $1.9^{\circ} \mathrm{C}$, which is the second highest increase in the world over the past 100 years. Furthermore, North Korea ranked seventh globally in the Global Climate Risk Index [23] and second in the Global Climate Risk Index [24]. Therefore, the study used the Köppen-Geiger climatic zones classification and the MME, of which applicability was verified to predict the impact of climate change on climatic zones of the Korean Peninsula under the RCP 8.5 scenario. The analysis result suggested that, with the changing climate, hot and humid, subtropical climate (Cfa), and the humid continental climate under the monsoon (Dfa) will be extending northward. In particular, the analysis of the coefficients of variation (CVs) of annual precipitation and mean temperature for the late 21 st century under the RCP 8.5 showed that precipitation had a low CV at the northwestern part of North Korea, and the temperature had the lowest CV at the southern coast of 


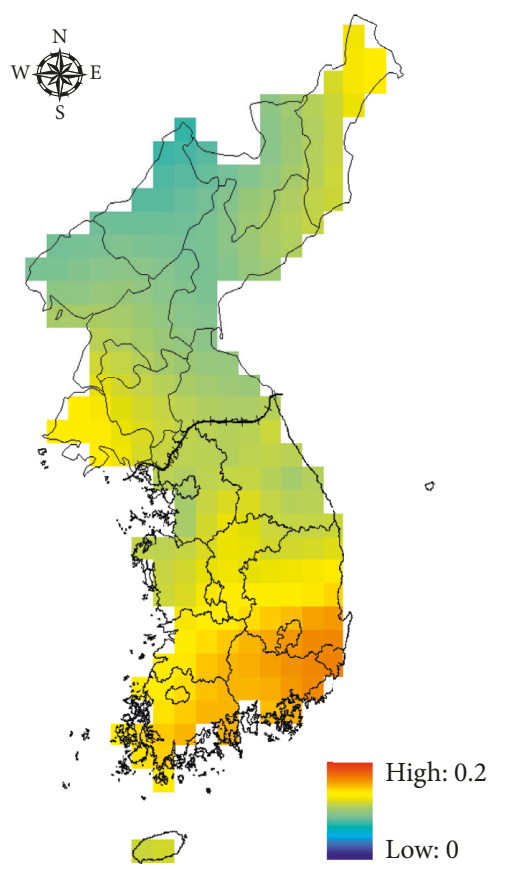

(a)

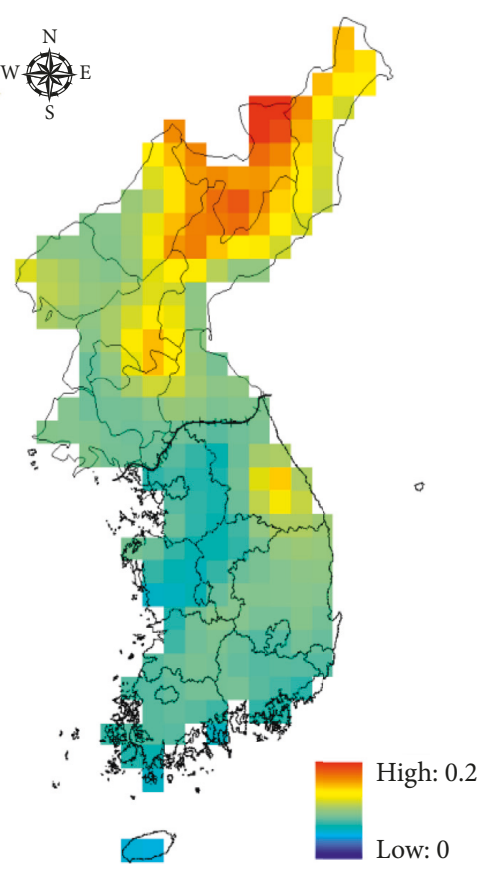

(b)

Figure 12: Coefficients of variation of 13 GCMs. (a) Precipitation. (b) Temperature.

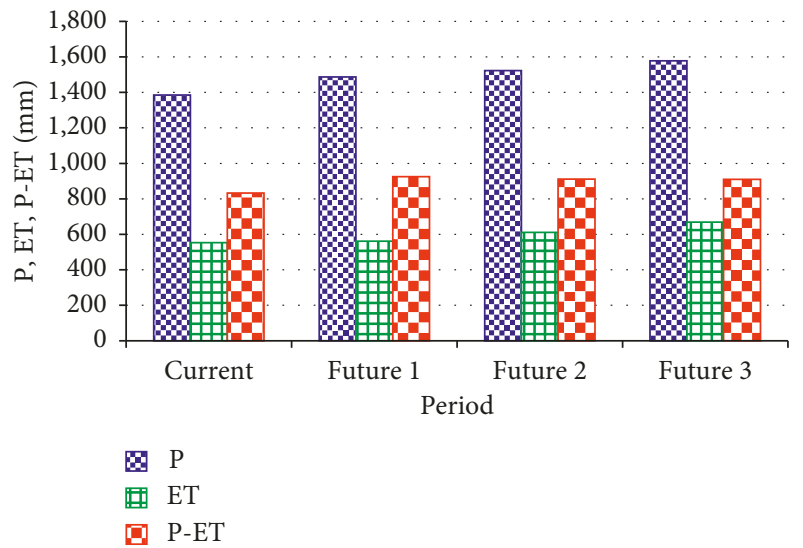

(a)

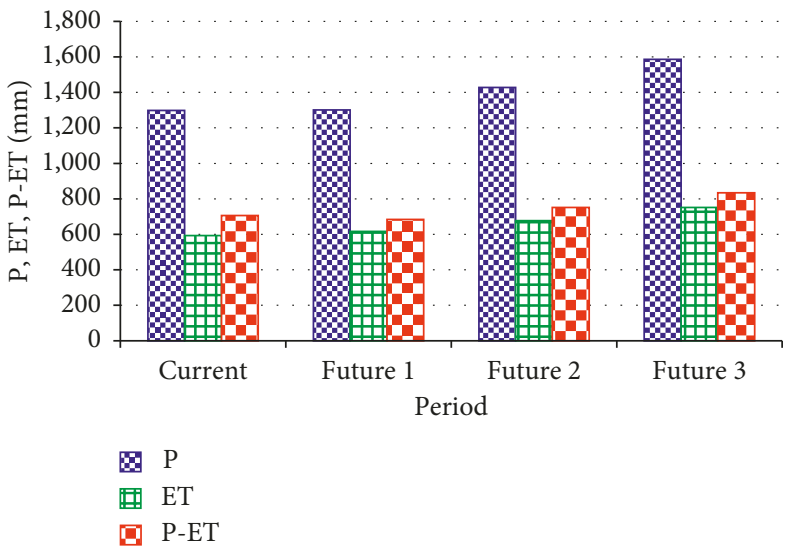

(b)

Figure 13: P, PET, and P-PET. (a) Gyeongsang-do. (b) Jeolla-do.

South Korea. The CV is the ratio of the standard deviation to the average, and a low CV indicates a slight discrepancy between scenarios and the average, which means again that the MME's average has a high possibility of occurring. The first step for the Köppen-Geiger climatic zones classification is grouping by temperature, and, accordingly, the climatic zone of the southern coast of South Korea will very likely shift to the Cfa.

A simple analysis was conducted to check the available water for the regions that are projected to experience a significant shift in their climatic zones in the future Korean Peninsula. With the increasing temperature, evapotranspiration showed a clear increasing trend with acceleration over time. However, the rise in evapotranspiration was not expected to enhance water availability, as it will likely be outweighed by increasing precipitation. Rather, because of the close positive relation between evapotranspiration and drought, more droughts are projected. Therefore, it is required to secure hydrological facilities for the effective use of available water to respond to droughts.

This research is significant in covering North Korea, for which related research examples can be hardly found as its study area, to produce a climate change scenario using the MME and predict climatic zones of the Korean Peninsula. With the current economic exchange being revitalized between the two Koreas, it is required to project shifts in hydrological cycles with the changing climate and provide scientific support for social and economic collaboration. The 
projection will also be helpful to produce detailed NorthSouth cooperation related to climate change. Results of this study are expected to support the effort of prioritizing regions in need of quantitative climate change projections for impact assessment, extreme climate, extreme droughts, and so on.

\section{Data Availability}

South Korea's downscaled climate change scenario data used in this study is provided by AIMS (APCC Integrated Modeling Solution, http://aims.apcc21.org/). North Korea's downscaled climate change scenario data is available from the corresponding author upon request.

\section{Conflicts of Interest}

The authors declare that they have no conflicts of interest.

\section{Acknowledgments}

This work was supported by the Korea Environmental Industry \& Technology Institute (KEITI) and grant-funded by the Ministry of Environment (83091). This study was supported by 2016 research grant from Kangwon National University (number-620160136).

\section{References}

[1] IPCC, "Climate change 2007: the physical science basis," in Contribution of Working Group I to the Fourth Assessment Report of the Intergovernmental Panel on Climate Change, Cambridge University Press, New York, NY, USA, 2007.

[2] Ministry of Environment, "Development of a forecasting model for change of biosphere with climate change and development of management techniques for vulnerable areas," Final Report, Ministry of Environment, Sejong City, South Korea, 2010.

[3] H. H. Seo and J. K. Kim, "Cultivation of fruit trees in Korea under the changing climate," Korean Society of Agricultural and Forest Meteorology, vol. 2005, no. 2, pp. 103-106, 2005.

[4] B. Sun and H. Wang, "A trend towards a stable warm and windless state of the surface weather conditions in northern and northeastern China during 1961-2014," Advances in Atmospheric Sciences, vol. 34, no. 6, pp. 713-726, 2018.

[5] W. Köppen, "The thermal zones of the earth according to the duration of hot, moderate and cold periods and to the impact of heat on the organic world," Meteorologische Zeitschrift, vol. 20, no. 3, pp. 351-360, 1884.

[6] A. N. Strahler, Physical Geography, John Wiley \& Sons, New York, NY, USA, 3rd edition, 1969.

[7] G. T. Trewartha and L. H. Horn, An Introduction to Climate, McGraw-Hill, New York, NY, USA, 5th edition, 1980.

[8] Y. A. Kwon, W. T. Kwon, K. O. Boo, and Y. G. Choi, "Future projections on subtropical climate regions over South Korea using SRES A1B data," Journal of Korean Geographical Society, vol. 42, no. 3, pp. 355-367, 2007.

[9] P. J. Guetter and J. E. Kutzbach, “A modified Köppen classification applied to model simulations of glacial and interglacial climates," Climatic Change, vol. 16, no. 2, pp. 193-215, 1990.
[10] G. S. Triantafyllou and G. E. Karniadakis, "Frequency selection and asymptotic states in laminar wakes," Journal of Fluid Mechanics, vol. 199, pp. 441-469, 1989.

[11] P. W. Suckling and M. D. Mitchell, "Variation of the Köppen C/D climate boundary in the Central United States during the 20th century," Physical Geography, vol. 21, no. 1, pp. 38-45, 2000.

[12] K. Fraedrich, F.-W. Gerstengarbe, and P. C. Werner, "Climate shifts in the last century," Climatic Change, vol. 50, no. 4, pp. 405-417, 2001.

[13] M. Wang and J. E. Overland, "Detecting arctic climate change using Köppen climate classification," Climatic Change, vol. 67, no. 1, pp. 43-62, 2004.

[14] C. Beck, J. Grieser, M. Kottek, F. Rubel, and B. Rudolf, "Characterizing global climate change by means of Koppen climate classification," Klimastatus Bericht 2005, pp. 139-149, 2005.

[15] J. Grieser, R. Gommes, and S. Cofield, On the Estimation of Monthly Precipitation Fields in Afghanistan, The Agromet Group, SDRN. FAO, Rome, Italy, 2006.

[16] I. U. Chung and S. H. Shin, "Observed change of climatic regions and desertification during the 20th century," KU Climate Research Institute, vol. 6, no. 1, pp. 23-44, 2011.

[17] A. J. Cannon, S. R. Sobie, and T. Q. Murdock, "Bias correction of GCM precipitation by quantile mapping: how well do methods preserve changes in quantiles and extremes?," Journal of Climate, vol. 28, no. 17, pp. 6938-6959, 2015.

[18] H.-I. Eum and A. J. Cannon, "Intercomparison of projected changes in climate extremes for South Korea: application of trend preserving statistical downscaling methods to the CMIP5 ensemble," International Journal of Climatology, vol. 37, no. 8, pp. 3381-3397, 2017.

[19] J. Räisänen and T. N. Palmer, "A probability and decisionmodel analysis of a multimodel ensemble of climate change simulations," Journal of Climate, vol. 14, no. 15, pp. 32123226, 2001.

[20] B. Rajagopalan, U. Lall, and S. E. Zebiak, "Categorical climate forecasts through regularization and optimal combination of multiple GCM ensembles*.," Monthly Weather Review, vol. 130, no. 7, pp. 1792-1811, 2002.

[21] A. E. Raftery, T. Gneiting, F. Balabdaoui, and M. Polakowski, "Using bayesian model averaging to calibrate forecast ensembles," Monthly Weather Review, vol. 133, no. 5, pp. 1155-1174, 2005.

[22] J. Sung, M. Kwon, J.-J. Jeon, and S. Seo, “A projection of extreme precipitation based on a selection of CMIP5 GCMs over North Korea," Sustainability, vol. 11, no. 7, p. 1976, 2019.

[23] S. Harmeling and D. Eckstein, Global Climate Risk Index 2013, Germanwatch, Bonn, Germany, 2013.

[24] S. Harmeling, Global Climate Risk Index 2009, Germanwatch, Bonn, Germany, 2009. 

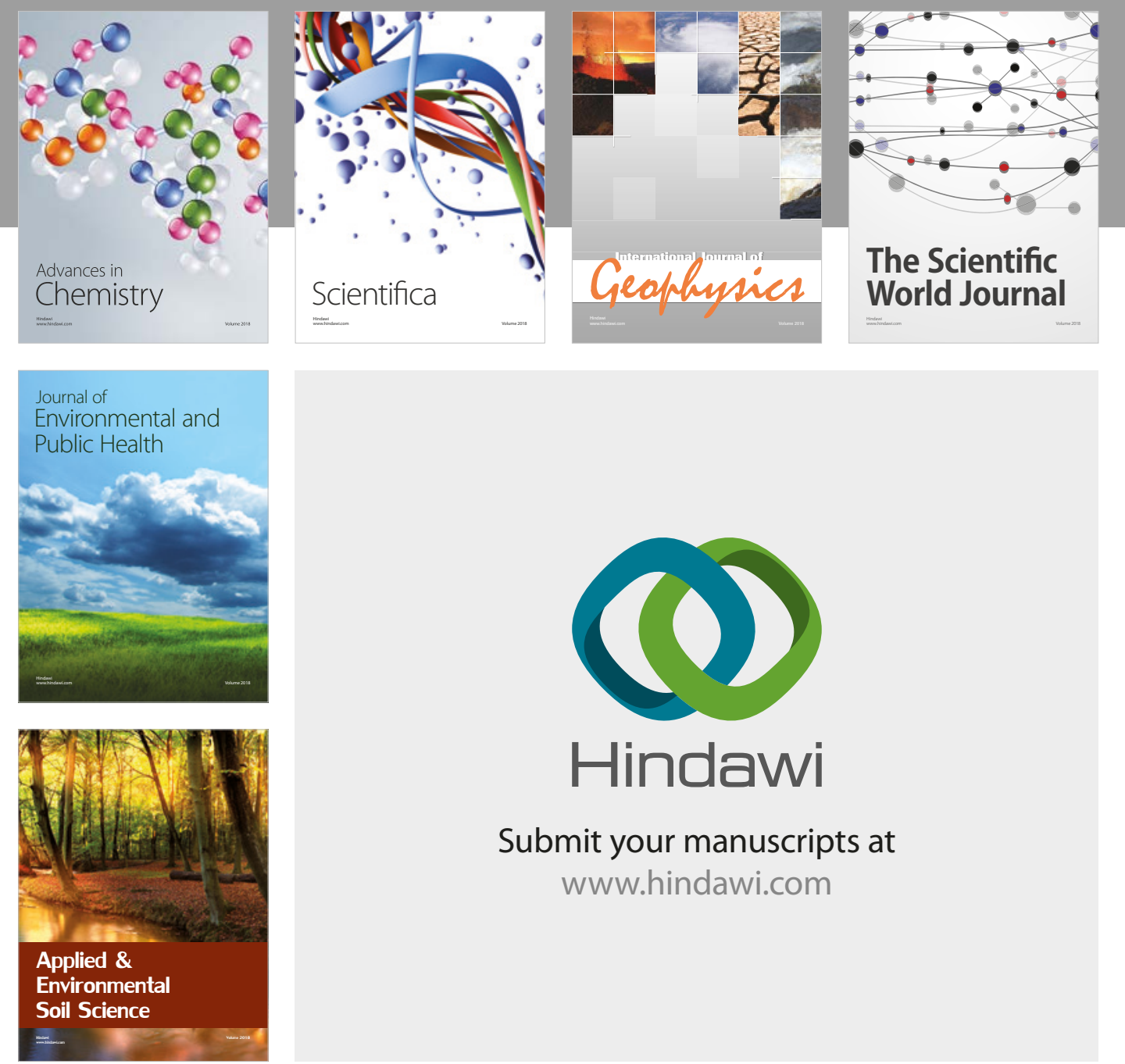

The Scientific

\section{World Journal}
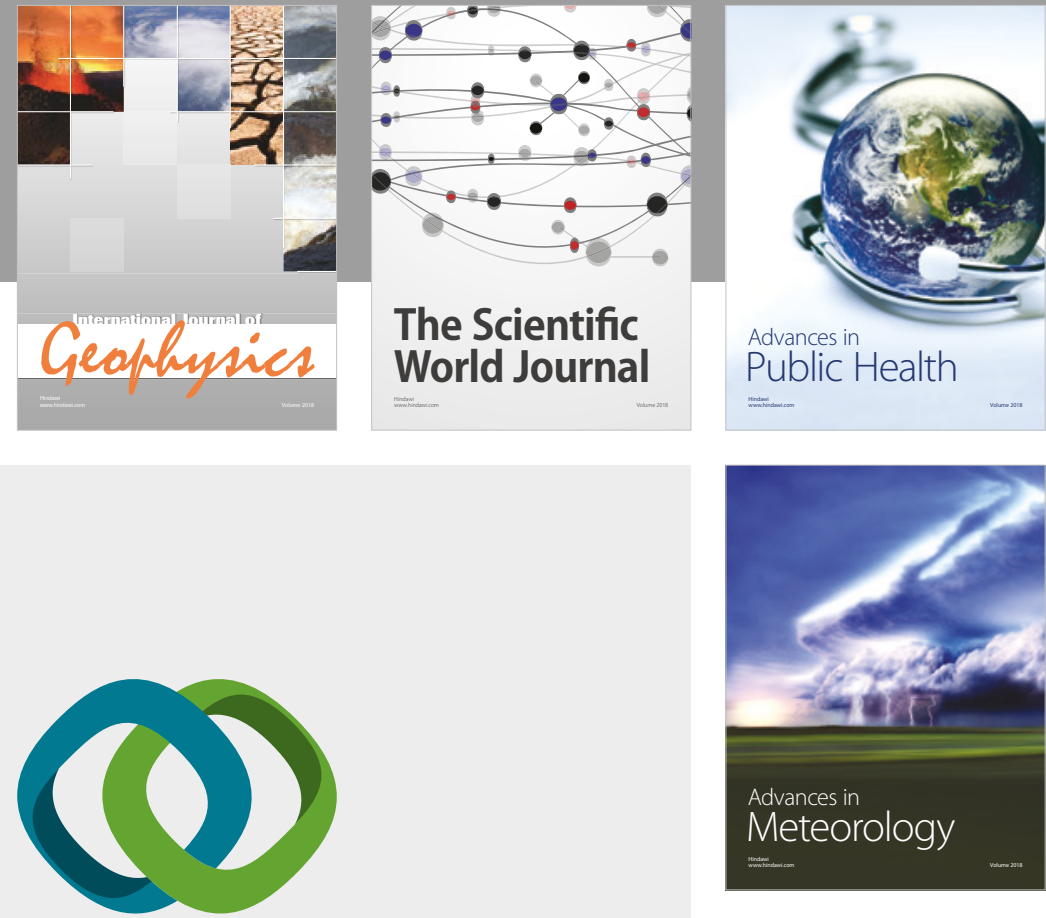

Advan

Public Health

\section{Hindawi}

Submit your manuscripts at

www.hindawi.com
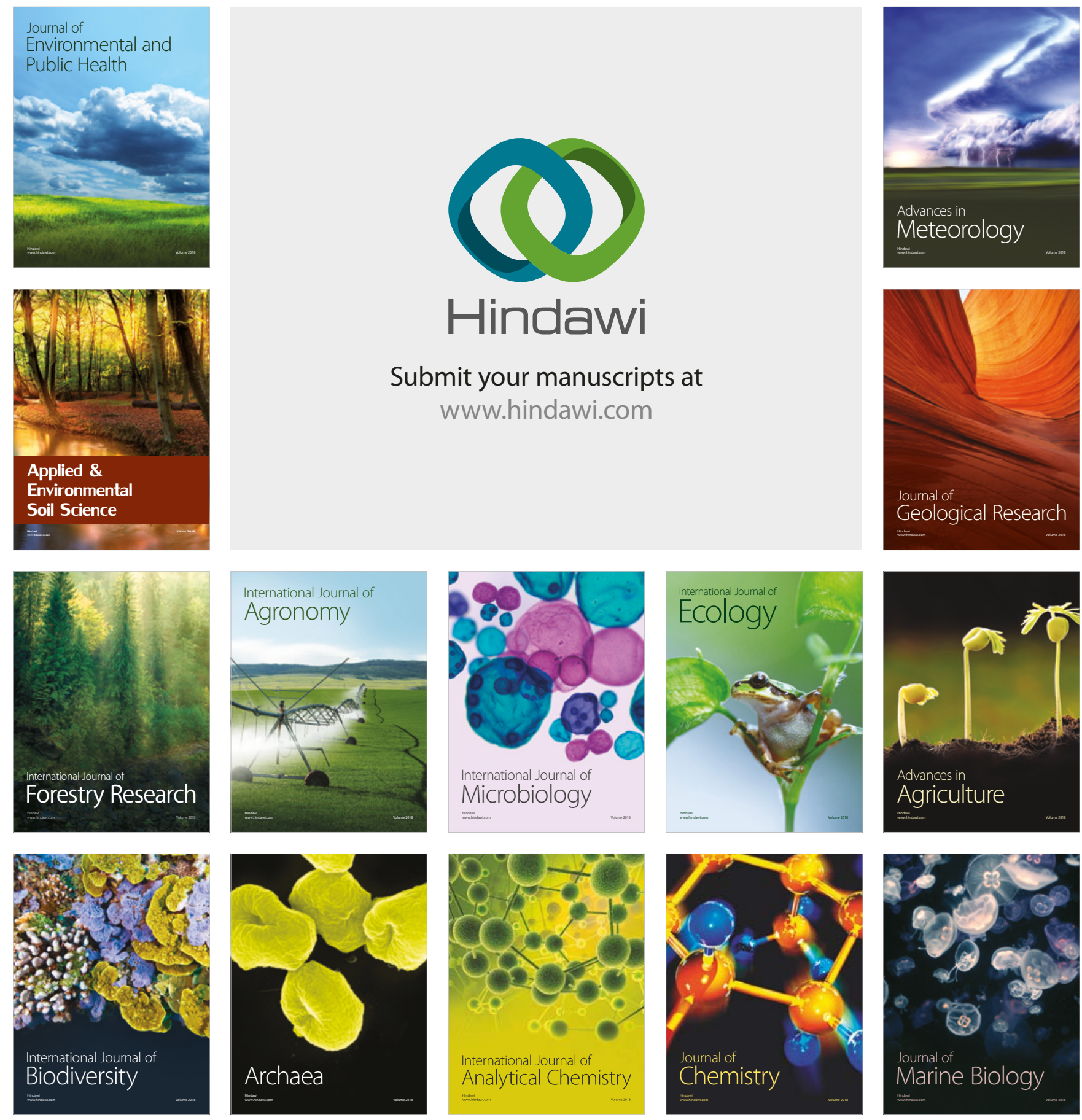